\title{
Learning to Teach Mathematics: Focus on Student Thinking
}

$\mathrm{T}$ HE FIELD OF MATHEMATICS EDUCATION has made great strides in developing theories and research-based evidence about how to teach elementary school mathematics in a way that develops students' mathematical understanding. Much of this progress has grown out of research projects that engage teachers in learning to teach mathematics. These projects have not only shown what is possible for teachers and students but have also provided insight into how to support teachers in their own learning. We use one particular research and development project, Cognitively Guided Instruction (CGD), as an illustration of how theory and research inform the leaching and learning of mathematics.

The key to CGI has been an explicit, consistent focus on the development of children's mathematical thinking (Carpenter, Fennema, \& Franke, 1996). This focus serves as the guide for understanding CGI's contributions as well as its evolution. ${ }^{1}$ Initiated over 15 years ago by Carpenter, Fennema, and Peterson, CGI sought to bring together research on the development of children's mathematical thinking and research on teaching (Carpenter, Fennema, Peterson, Chiang, \& Loef, 1989). This research project engaged first-grade teachers with the research-based knowledge about the development of children's mathematical think-

Megan Loef Franke is associate professor of education at the University of Califomia, Los Angeles; Elham Kazemi is assistant professor of education at the University of Washington, Seattle. ing. We studied the teachers' use of this knowledge within their classroom practice and examined the changes in teachers' beliefs and knowledge.

This work created a rich context for our own learning as well as for the teachers. We learned a great deal about teachers' use of children's thinking, teacher learning, and professional development. Since the initial project, our understandings and our work with teachers and students have continued to evolve. We now work with $\mathrm{K}-5$ teachers across a number of different content areas (Franke \& Kazemi, in press; Kazemi, 1999). Our learning reflects much of the learning occurring in the field. ${ }^{2}$

In this article, we divide our learning about CGI into two sections. These sections represent an ongoing shift in our thinking from a consistent cognitive paradigm to a more situated paradigm. These different notions of learning have influenced our views of student and teacher learning and how to maximize that learning. We tell this story by describing our initial CGI work and what we learned about students and teachers. We then elaborate by describing and characterizing our current work and how that has influenced our learning about creating a focus on students' mathematical thinking within professional development.

\section{A Cognitive Begimning}

CGI began by providing teachers with knowledge, derived from research, about the development of children's mathematical thinking and letting the 
teachers decide how to make use of that knowledge in the context of their own teaching practice. We shared this knowledge with teachers in a range of mathematical content areas. However, what we shared was not a random set of ideas but rather an organized set of frameworks that delineated the key problems in the domain of mathematics and the strategies children would use to solve them. The frameworks provided teachers the opportunity to understand how this knowledge about the development of children's thinking fits together so the teachers could make it their own (Carpenter, Fennema, \& Franke, 1996; Fennema et al., 1996).

The teachers discuss CGI as a philosophy, a way of thinking about the teaching and learning of mathematics, not as a recipe, a prescription, or a limited set of knowledge. CGI teachers engage in sense making around children's thinking. They continually evaluate their understanding, adapt and build on their knowledge, and figure out how to make use of it in the context of their ongoing practice.

Although it fails to completely capture what CGI is about, understanding the knowledge we share with teachers and how it fits into organized frameworks that are related to one other is critical to understanding CGI. Constructing models of children's thinking entails focusing on organized, principled knowledge about problems within the various content domains, along with the range of strategies children often use to solve the problems. The strategies discussed with the teachers are related to one another, both within and across problems. The strategies build within problems, in terms of mathematical sophistication, while across problems classes of strategies exist. For example we can take a multiplication problem and detail (a) the strategies students will most likely use to solve it, (b) how those strategies build on each other, and (c) how the solutions relate to solutions of other grouping problems and problems using other operations.

To solve the grouping problem presented in Figure 1, a child could use a range of strategies. However, these strategies often fali into one of four classes. A child could initially solve the problem by direct modeling the action in the problem. Here the child physically represents the number of boxes and the number of crayons in each box. The counting strategy builds on the direct modeling strategy as the child continues to represent the ac- tion in the problem but does so by physically keeping track of the number of groups and counting up the number in each group using skip counting. The derived fact strategy no longer models the action in the problem but rather makes use of what the child already knows about multiplication facts. Recall shows the child knows the fact and does not need to represent the action.

\section{Grouping problem:}

Tessa has 6 boxes of crayons. Each box contains 5 crayons. How many crayons does Tessa have altogether?

\section{Possible solutions:}

Direct modeling: Draws out 6 boxes and makes 5 marks in each box. Counts the total number of marks.

Counting strategy: Counts by 5 's $(5,10,15,20,25,30)$ keeping track of the 6 numbers in the counting sequence on his or her fingers.

Derived fact: Knows 5 times 5 is 25 so 6 times 5 would be one more 5 that would be 30 .

Recalled fact: Knows that 6 times 5 is equal to 30 .

Figure 1. A grouping problem and possible strategies for solving it.

Knowing the sequence of strategies allows teachers to interpret why a particular problem may be difficult for a child. If we changed the numbers in the problem to six boxes and seven crayons in each box, we would not create much difficulty for a child who was direct modeling. However, we might for a child using a counting strategy, as the child may not be as efficient at counting by sevens and may use a less efficient counting strategy or direct model. Knowing the sequence of strategies enables teachers to create problems that challenge their students' thinking. At the same time, it avoids engaging students in strategies that do not make sense to them.

The parallels in strategy development across problem domains help teachers understand the mathematical ideas associated with those patterns and interpret the mathematical understanding of the children in their own classrooms (Carpenter et al., 1996). For instance, teachers do not often think about posing a problem such as the following:

Keisha had some markers. Her grandmother went shopping and bought Keisha 6 more markers. When Keisha counted all of the markers she now had, she found that she had 14 markers. How many markers did Keisha have before her grandmother gave her the new ones? 
Knowing that direct modeling is the least sophisticated strategy for solving many addition and subtraction problems enables a teacher to see that the direct modeling approach will not make it easy for children to solve this particular problem. Those who use direct modeling will not know how many counters to put in their initial set and thus may not know how to get started. A child would need to begin by putting out some counters (the number of counters the child thinks represents the "some" in the problem), add 6 to that set, and count to see if there are 14 counters altogether. If not, the child would need to adjust the initial set and begin the process again.

Understanding the relationship between an initial unknown quantity and the direct modeling strategy allows the teacher to think beyond this particular problem and about what can make problems difficul for children to solve and why. As teachers engage in listening to their students' thinking, they learn more about possible problems to pose, strategies to expect, and relationships that exisl between problems and strategies. This new knowledge is connected with their existing knowledge as they continue to elaborate and build their frameworks. CGI teachers have interacted with knowledge about children's thinking in the donains of addition and subraction, multiplication and division, place value, algebra, fractions, and geometry.

\section{Results of early CGI work}

Our goal in our initial CGI work was to share this research-based knowledge about the development of children's mathematical thinking with teachers, provide them an opportunity to think about what it might mean for their practice, and then watch to sce what teachers did with the knowledge and how this affected their students' learning. The teachers surprised us. While we anticipated teacher learning, changes in teachers' classroom practices, and resulting student learning, we did not anticipate the scope of the learning that occurred or the ownership the teachers took in disseminating CGI.

Teachers' expectations of their students' mathematical understanding changed dramatically. First-grade teachers saw that their students, whether in a midwestern city or a large urban center, could solve word problems often omitted from the cur- ricuhum until third grade. Teachers recognized that their students solved the posed problems using a range of mathematical strategies, strategies they never expected to see in their own students. Teachers realized they needed to listen to their students' mathematical explanations, create strategies and questions to elicit those explanations, and understand enough about children's thinking and the content to know what to do with what they heard.

In all of our work with $\mathrm{K}-5$ teachers, we have found them to be surprised by their students' mathematical thinking and by how often the students said what the research indicated they would say. Teachers began listening more and teling less, regularly eliciting students" mathematical thinking and anticipating multiple strategies. While not all teachcrs found it easy to use what they heard from students to make instructional decisions, nost teachers found ways to encourage students to elaborate their mathematical thinking.

The students' learning paralleled that of the teachers. The students in CGI classrooms could solve a wider variety of word problems, used a wider range of strategies, and knew their number facts at a better recall level than their control group counterparts. In our longitudinal study (Fennema et al., 1996), we found that students on average made a grade level gain in achievement: The second graders performed as the third graders had at the beginning of the study, and so on. Additionally, the students in CGI classrooms reported being more confident and better able to understand mathematics.

Listening to students' mathematical thinking had another benefit. It transformed teachers into learners. They learned in the context of their practice about the teaching and leaming of mathematics and became engaged in what Richardson (1990, 1994) terms "practical inquiry." Teachers struggled to make sense of the development of their students' mathematical thinking and how that related to their instructional decisions. Professional development happened inside and not just outside teachers' classroom doors.

\section{Generative growth}

As we studied teachers involved in our longitudinal study 4 years after the professional development ended, we had the opportunity to learn more about practical inquiry and teacher growth. We were able 
to track how teachers had sustained themselves or continued to grow professionally since our last data collection in the longitudinal study. We termed the patterns we observed generative growth.

We drew from the work on the development of student understanding in mathematics to conceptualize ongoing teacher learning. One distinguishing characteristic of learning with understanding is that it is generative (Carpenter \& Lehrer, 1999; Greeno, 1988; Hicbert \& Carpenter, 1992). Generativity refers to individuals' abilities to continue to add to their understanding. When individuals learn with understanding, they can apply their knowledge to learn new topics and solve new and unfamiliar problems. When individuals do not learn with understanding, each new topic is learned as an isolated skill that can be used only to solve problems explicitly covered by instruction.

A second defining characteristic of learning with understanding is that knowledge is rich in structure and connections. When knowledge is highly structured, new knowledge can be related to and incorporated into existing networks of knowledge. This is not a matter of adding knowledge incrementally element by element. Learning with understanding goes beyond connecting new knowledge to existing knowledge and includes reorganizing knowledge to create rich integrated knowledge structures. A third factor in learning with understanding is that learners see learning as driven by their own inquiry. Carpenter and Lehrer (1999), for example, propose that learners must perceive their knowledge as their own, believing that they can construct knowledge through their own activity.

Using this way of conceptualizing generative growth allowed us to examine the degree to which teachers were engaged in generative growth and to add details to what generative growth looks like in CGI teachers. We found that indeed a number of the CGI teachers were engaged in generative growth. These teachers could detail their students" mathematical thinking, had a way of organizing those details that highlighted the principles underlying the thinking, and saw the knowledge as their own to adapt and create.

Our initial definition of generative learning focused on characterizing the nature of the knowledge teachers were continually developing. It was clear that teachers were redefining how they inter- acted with their students, with their colleagues, and with mathematics. Yet in our initial analysis of teacher learning, we did not explicitly theorize about the nature of teachers" practical inquiry or the way it changed their way of being in the classroom and beyond.

\section{Considering a Situated Approach}

As we began to work with teachers and explicitly support the development of generativity, we found ourselves limited by our cognitive approach. Teachers were learning along with each other, their students, and us. We began to account for and theorize about teachers' practice as occurring in their classrooms, professional development sessions, and conversations with each other, their principal, and parents. Situated theory provided a lens for beginning to understand how a focus on students' mathematical thinking supported teacher and student learning and for creating professional opportunities that would enhance that learning.

Drawing on the work of Lave, Wenger, Cobb, Wertsch, Rogoff, and others, we now struggle to recast our thinking about teacher learning and generativity to highlight learning within a community of practice (Cobb, 1999; Lave, 1996; Lave \& Wenger, 1991; Rogoff, 1994, 1997; Wenger, 1998; Wertsch, 1991). Lave, Wenger, and Rogoff have described learning as being evident in shifts in participation in communities of practice. A shift in participation does not merely mark a change in a participant's activity or behavior. It involves a transformation of roles and the crafting of a new identity, one that is linked to new knowledge and skill.

The situated perspective for us highlights teachers' appropriation of knowledge as they participate in communities of practice. The communities of practice become critical to understanding teacher learning. The artifacts that are used as we engage together can afford or constrain participation and support or not support teacher learning. ${ }^{3}$ We became interested in understanding teachers' changing participation and identities as they engaged in a particular community of practice, where mathematics is central, and the ways in which tools (in our case, student work) support or constrain the practices and reasoning of those participating 
(Saxe, 1991; Wertsch \& Kanner, 1992). This view of teacher learning pushed our initial notions of generativity.

\section{Rethinking professional development}

Taking on this more situated stance pressed us to rethink our engagement with teachers and create professional development opportunities that reflected this perspective. The professional development teachers engage in is a part of their practice. Professional development sessions constitute a site where teachers and professional developers engage in learning together. Understanding the professional development community of practice provides an opportunity to better understand teachers' learning and legitimizes the work of teaching occurring within the professional development.

In applying our situated stance, we created a new community of practice with the teachers and administrators from a single school site and ourselves (the professional development/research team). The focus of this particular community of practice remained on understanding the details of students' mathematical thinking; however, here we focused on the mathematical thinking of teachers' own students and tracked the emergence of that thinking within the context of the teachers' classroom practice. We conjectured that a focus on teachers' own students would facilitate a compelling link between the classroom and professional development communities (Franke \& Kazemi, in press).

\section{Teacher work groups}

We began our work by getting to know the existing community. We spent time in the school taking with teachers, teaching a university mathematics methods course, and helping out when needed. A year later we approached the teachers and administrators about working together on a consistent basis. We created four teacher work groups, each consisting of approximately 12 teachers from across grades $K-5$ who worked together on a monthly basis. We hoped to create conditions where teachers could establish a new dimension of their practice centered on examining student work and their classroom practices.

Each month the teachers posed a work-group mathematics problem to their students and brought their student work to the meeting. A typical workgroup problem read as follows:

Yvette collects baseball cards. She had 8 Dodger cards in her collection. How many more Dodger cards does Yvette need to collect so that she will have 15 Dodger cards altogether?

The teachers were given this problem and the same problem with the numbers 67 and 105. They could adapt the numbers and the context but were asked not to change the structure of the problem. The student work provided the basis for the work-group discussion. The teachers shared their students' solutions to the problem, compared the mathematical understanding of each strategy and how the strategies may build on each other, and described how particular strategies were elicited and developed. The teachers were asked to carefully detail the student thinking, create ways to make sense of that thinking, and situate the students' thinking within particular classroom interactions.

As we facilitated the work-group meetings, our goal was to scaffold the conversation in a way that allowed the teachers to create a common language and focus for taking about the teaching and learning of mathematics. Initially the group discussions were dialogues between the facilitator and one member of the work group. Over time the discussions became conversations among the members of the group. We also engaged the teachers and administrators outside the context of the workgroup meeting. We spent time in teachers' classrooms, walked the hallways, and visited the lunchroom. We wanted to get to know the teachers and their students. We wanted to be seen as a part of the school community.

In visiting classrooms, we helped the teachers see that we wanted to get to know their students, not evaluate their teaching. We stopped in during math time to see what their students were doing and get some sense of who the students were and what they were thinking, rarely staying for an entire lesson. We also stopped by each month prior to the work-group meeting to give the teachers the problem for the next meeting. While we could have provided the problem at the end of the previous work-group meeting, we used this as another point of contact and an opportunity to engage in conversation with the teachers outside the context of the 
meeting itself. We often stopped in the hallway to chat with teachers about their students' mathematical thinking. We found that teachers began talking more with each other about what their students were doing and saying during math class.

We also spent time with the principal. She understood our work with the teachers in terms of both content and process. She valued our participation in the school community and paved the way for community building. She used school meeting time for the work-group meetings so teachers would not give up their own time or part of their school day with students. And she evaluated the teachers by having them bring student work to her three times during the year, rather than observing in their classrooms. So both the details of structuring the meetings and the substance of her work with the teachers supported the development of the conmunities of practice.

\section{Results from work groups}

Working with one school over a 4-year period enabled us to characterize the communities of practice and shifts in participation within them. The teachers in the work groups became much better at detailing students' mathematical thinking. They not only detailed the strategies the students used but expanded the details to include the pedagogical practices that supported that student thinking. Thus, in detailing the student thinking for the group, teachers included rich descriptions of the questions asked to elicit that thinking, the responses of other students, and the work that came before the shared interaction.

The teachers also developed ways of talking with each other about the relationships across the strategies that highlighted the mathematical ideas being developed. Teachers could talk about the relationship between a strategy used in multiplication and a strategy a child used in solving a multi-digit addition problem, and could describe the common, place value understanding demonstrated across the strategies.

Beyond the ways teachers talked about student thinking, we noted shifts in the stances teachers took in their participation. Teachers began to see themselves as able to contribute to the group as teachers of mathematics with knowledge and skills to share. One teacher in our initial conversation described herself as having nothing to offer her work group. Her expertise was in literacy, and she felt she knew little about the teaching of mathematics. She was there to listen, and she opted not to pose the initial work-group problem to her class.

By the end of the year, however, she not only consistently posed the work-group problem to her class but she also used what she learned from the students to pose a series of new problems. She brought student work from all of her problems posed to the work-group meeting, and shared and discussed insights with her colleagues. She now leads the group as a facilitator. The teachers, like the one described, developed a sense of themselves as learners. They used the work group as a place to talk about their experimentation with the problems and describe and enrich their learning from their experimentation.

Teachers' participation in their classrooms also changed. Teachers began to see the work-group problem as a part of their ongoing practice rather than something separate they had to get done for the meeting. They developed ways to elicit and listen to their students' mathematical thinking. They integrated the work-group problem into their classroom practice and saw experimentation as a part of their teaching practice. Yet, the changes in their practice were not limited to their classrooms or the work groups themselves. Teachers began to talk with each other outside of the work groups about students' thinking and their teaching practices. They took on leadership roles within the school and the district. Four of the teachers joined the district math committee, and proposed and changed the district math standards. The teachers developed identities as mathematics teachers with expertise to offer. They reported they could no longer teach at a school without the perspective on teaching and learning of mathematics that existed at their school. And most importantly, the work groups continue, 2 years after we discontinued our participation.

We learned that generative growth is not about a set of characteristics the teacher possesses; it is about teachers' developing knowledge and skills and the identities that evolve in relation to the knowledge and skills. Teachers engaged in generative growth within our project all possessed substantial knowledge about the development of students' mathematical thinking. They could detail the knowledge in a 
way that included the context in which the strategy occurred, the mathematical ideas involved, and their beliefs and values about the teaching and learning of mathematics. These new understandings provided the support for teachers' developing identities. We noticed in our previous work that the teachers engaged in generative growth saw their classrooms as places for experimentation and their own learning. We see in our current work that the way in which the teachers see themselves and negotiate their identity becomes critical to their generativity.

Taking a situated approach to understanding generativity changed our interactions with teachers and enriched our understanding of the characteristics of generative growth. We found ways to begin to account for teachers' different learning trajectories by tracking the interplay between their classroom and professional development experiences. We paid attention to how teachers' participation both contributed to the development of the classroom and work-group communities and was shaped by it. A situated perspective allowed us to deepen our understanding of why collaborating in detailed analyses of students' mathematical work and experimentation in the classroom supported teachers' generative growth.

\section{Conclusion}

Student thinking remains at the core of our CGI work. What has changed is how we conceptualize what it means to engage with student work, how we come to understand what teachers and students are learning, and how we create opportunities for teacher and student learning.

Focusing on students' mathematical thinking remains a powerful mechanism for bringing pedagogy, mathematics, and student understanding together. As teachers struggle to make sense of their students' thinking and engage in practical inquiry, they elaborate how problems are posed, questions are asked, interactions occur, mathematical goals are accomplished, and learning develops. The details surrounding these issues are seen in support of one another, not separate from one another. Teachers' experimentation around student thinking becomes part of their practice. Whether talking with other teachers or with their students, teachers see a clear relationship between their learning and their students' leaming.
Some researchers have suggested that CGI has been too narrowly focused on the cognitive aspects of prescribed mathematical domains. We would argue, however, that the focused CGI work forms the basis for our understanding of teacher and student learning within a situated perspective. ${ }^{4}$ While our current work with teachers and our research methods may look guite different from when we began over 15 years ago, we draw heavily on the details of student thinking elaborated in that work, the organization of those details, and the characterization of teacher learning. The knowledge developed through the earlier CGI work provides the basis for how we structure our interactions with teachers and guides our facilitation as we engage teachers in discussing the details and avoid surface-level discussions of student thinking.

Understanding the details elaborated through the early CGI work also enabies us to look with a particular focus at understanding the stories teachers tell and the identities the stories support. While our theoretical perspectives are shifting somewhat, those perspectives have illuminated our early work and provided a way to better understand ongoing learning within communities of practice.

\section{Notes}

The research reported in this article was supported in part by a grant from the Department of Education office of Educational Research and Improvement (OER) to the National Center for Improving Student Learning and Achievement in Mathematics and Science (R305A60007-98). The opinions expressed in this article do not necessarily reflect the position, policy, or endorsement of the Department of Education, OERI, or the National Center.

1. CGI is one of a number of projects drawing on student thinking to focus and define the teaching and learning of mathematics (see, for example, Barnett \& Sather, 1992; Borko \& Putnam, 1996; Brown \& Campione, 1996; Lehrer \& Schauble, 1998; Schifter, 1997; Warren \& Rosebery, 1995).

2. Certainly, we do not want to treat CGI as an isolated example. CGI developed in the way that it has because of our interactions with our colleagues (researchers and teachers), from our readings of the work of others in the field, and the evolution of theoretical notions available. CGI occurred in a context of exciting developments in mathematics education and is a product of the various projects and people doing parallel and non-parallel work. 3. A number of researchers within mathematics education have developed this situated perspective as they characterize and study teachers, students, and classrooms (Boaler, 2000; Cobb, 1999; Stein \& Brown, 1997). 
4. And here, clearly we have only begun to explore these perspectives in relation to teacher and student learning of mathematics in elementary schools.

\section{References}

Boaler, J. (2000). Exploring situated insights into research and learning. Journal for Research in Mathematics Education, 31, 113-119.

Borko, H., \& Putnam, R. (1996). Learning to teach. In D. Berliner \& R. Calfee (Eds.), Handbook of educational psychology (pp. 673-708). New York: Macmillan.

Barnett, C.S., \& Sather, S. (1992, April). Using case discussions to promote changes in beliefs among mathematics teachers. Paper presented at the annual meeting of the American Educational Research Association, San Francisco.

Brown, A., \& Campione, J. (1996). Psychological theory and the design of innovative learning environments: On procedures, principles, and systems. In L. Schauble \& R. Glaser (Eds.), Innovarions in leaming (pp. 289-326). Hillsdale, NJ: Erlbaum.

Carpenter, T.P., Fennema, E., \& Franke, M.I. (1996). Cognitively Guided Instruction: A knowledge base for reform in primary mathematics instruction. $\mathrm{El}$ ementary School Joumal, $97(1), 1-20$.

Carpenter, T.P., Fennema, E., Peterson, P.I., Chiang, C.P., \& Loef, M. (1989). Using knowledge of children's mathematics thinking in classroom teaching: An experimental study. American Educutional Research Journal, 26, 499-531.

Carpenter, T., \& Lehrer, R. (1999). Teaching and learning mathematics with understanding. In E. Fennema \& T.A. Romberg (Eds.), Mathematics classrooms that promote understanding (pp. 1932). Mahwah, NJ: Erlbaum.

Cobb, P. (1999). Individual and collective mathematical development: The case of statistical data analysis. Mathematical Thinking and Leaming, 1, 5-43.

Fennema, E., Carpenter, T.P., Franke, M.L., Levi, L., Jacobs, V., \& Empson, S. (1996). A longitudinal study of learning to use children's thinking in mathematics instruction. Journal for Research in Mathematics Education, 27, 403-434.

Franke, M.L., \& Kazemi, E. (in press). Teaching as learning within a community of practice: Characterizing generative growth. In. T. Wood \& B. Nelson (Eds.), Beyond classical pedagogy in elementary mathematics: The nature of facilitative teaching. Mahwah, NI: Erlbaum.

Greeno, J. (1988). Situations, mental models and generative knowledge. (Rep. No. IRL 88-0005). Palo Alto, CA: Institute for Research on Learning.

Hiebert, I., \& Carpenter, T.P. (1992). Learning and teaching with understanding. In D. Grouws (Ed.), Handbook of research on mathematics teaching and learning (pp. 65-97). New York: Macmillan.
Kazemi, E. (1999). Teacher learning within communities of practice: Using students' mathematical thinking to guide teacher inguiry. Unpublished doctoral dissertation, University of California, Los Angeles.

Lave, I. (1996). Teaching, as learning, in practice. Mind, Culture, and Activity, 3, 149-164.

Lave, J., \& Wenger, E. (1991). Situated learning: Legitimate peripheral paricipation. Cambridge, UK: Cambridge University Press.

Lehrer, R., \& Schanble, L. (1998). Modeling in mathematics and science. Unpublished manuscript, Wisconsin Center for Educational Research, Madison.

Richardson, V. (1994). Conducting reseatch on practice. Educational Researcher, 23(5), 5-10.

Richardson, V. (1990). Significant and worthwhile change in teaching practice. Educational Researcher, 19(7), 10-18.

Rogoff, B. (1994). Developing understanding of the idea of communities of learners. Mind, Culture, and Activity, 1, 209-229.

Rogoff, B. (1997). Evaluating development in the process of participation: Theory, methods, and practice building on each other: In E. Amsel \& A. Renninger (Eds.), Change and development: Issues of theory, application, and method (pp. 265-285). Mahwah, NJ: Eribaum.

Saxe, G. (1991). Culture and cognitive development: Studies in mathematical understanding. Hillsdale, NJ: Erlbaum.

Schifter, D. (1997, April). Developing operation sense as a foundation for algebra. Paper presented at the annual meeting of the American Educational Research Association, Chicago.

Stein, M.K., \& Brown, C.A. (1997). Teacher leaming in a social context: Integrating collaborative and institutional processes with the study of teacher change. In E, Fennema \& B.S. Nelson (Eds.), Mathematics teachers in transition (pp. 155-191). Mahwah, NJ: Erlbaum.

Warren, B., \& Rosebery, A.S. (1995). Equity in the future tense: Redefining relationships among teachers, students and science in language minority classrooms. In W. Secada, E. Fennema, \& L. Adajian (Eds.), New directions for equity in mathematics education (pp. 298-328). New York: Cambridge University Press.

Wenger, E. (1998). Communities of practice: Leaming, meaning, and identity. Cambridge, UK: Cambridge University Press.

Wertsch, J.V. (1991). Voices of the mind: A sociocultural approach to mediated action. Cambridge, MA: Harvard University Press.

Wertsch, J.V., \& Kanner, B.G. (1992). A sociocultural approach to intellectual development. In R.J. Sternberg \& C.A. Berg (Eds.), Intellectual development (pp. 328-349). Cambridge, UK: Cambridge University Press. 


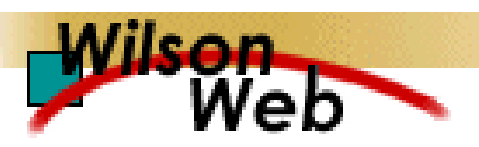

\section{COPYRIGHT INFORMATION}

TITLE: Learning to teach mathematics: focus on student thinking SOURCE: Theory into Practice 40 no2 Spr 2001

WN: 0110500374004

The magazine publisher is the copyright holder of this article and it is reproduced with permission. Further reproduction of this article in violation of the copyright is prohibited.

Copyright 1982-2001 The H.W. Wilson Company. All rights reserved. 